\title{
Preposição Diante do Pronome Relativo no Português Brasileiro e Europeu
}

\author{
(Preposition Ahead of the Relative Pronoun in the \\ Brazilian and European Portuguese)
}

Dorotea Frank Kersch
(Unisinos)

Resumo: Neste estudo se investiga o apagamento da preposição diante do pronome relativo entre falantes de português do extremo sul do Brasil e Norte do Uruguai; os resultados são comparados a dados do português europeu. Os material utilizado é todo de língua falada: dois estilos do projeto ADDU-Atlas Lingüístico Diatópico y Diastrático del Uruguay (pergunta-resposta e conversa livre), cinco entrevistas do Projeto NURC-Norma Urbana Culta) Porto Alegre), além de entrevistas do projeto Português Fundamental, do português europeu. A análise das amostras sugere que a tendência de apagar a preposição diante do pronome relativo, comum no $P B$, no espanbol e no italiano, não é tão freqüiente no PE, em que, até mesmo nas circunstâncias de tempo e lugar, a preposição em é mantida. Observou-se também que, tanto no Potuguês Brasileiro quanto no Europeu é comum o uso do relativo que para substituir um constituinte preposicionado para esquivar-se da construção de uma relativa complexa.

PALAVRAS-CHAVE: preposição; pronome relativo; apagamento; ambigüidade.

ABstract: This study investigates the deletion of the preposition that precedes the relative pronoun by Portuguese speakers of the south of Brazil and the north of Uruguay; the results are compared to data of European Portuguese. The material used is entirely of the spoken language: two styles taken from the project called ADDU-Atlas Lingïistico Diatópico y Diastrático del Uruguay (questions and answers, and free conversation), five interviews taken from the project known as NURC (Standard spoken language), in addition to interviews from the project called Português Fundamental (or Basic Portuguese spoken in Portugal). The analysis of the samples suggests that the tendency to delete the preposition ahead of the relative pronoun, common in Brazilian Portuguese, Spanish and Italian, is not so frequent in European Portuguese, where, even in the circumstances of time and space, the preposition in is preserved. It was also noticed that 
in both Portuguese varieties the use of the relative pronoun that is frequently used to replace a propositioned constituent to avoid the construction of a complex relative clause. Key-words: preposition; relative pronoun; deletion; ambiguity.

\section{Introdução}

Em estudo diacrônico do uso de orações relativas nos séculos XVIII e XIX no português brasileiro, Tarallo (1983) verificou que, em se tratando de constituinte preposicionado, a relativa cortadora aos poucos vem substituindo a relativa padrão. Isso o autor também confirmou no mesmo trabalho, quando analisou as relativas produzidas, na década de 1980, na fala urbana de São Paulo.

Este trabalho objetiva estudar tal fenômeno com base em amostras dos estilos pergunta-resposta e conversa livre do acervo do Atlas Lingüístico Diastrático y Diatópico del Uruguay - ADDU-Norte, que contempla a fronteira bilíngüe entre Brasil e Uruguai e do projeto NURC-Porto Alegre, que reúne dados de língua falada de falantes cultos, além das entrevistas do projeto Português Fundamental, do português europeu. Aqui se busca saber se, em comparação com o português brasileiro, no português europeu os falantes apagam a preposição diante do pronome relativo e se a relativa padrão, com o movimento do constituinte preposicionado para encabeçar a relativa, também é evitada pelos falantes daquela variedade.

Para este estudo, estabelecemos as seguintes hipóteses:

a) Relativas simples, com o uso de QUE, são mais freqüentes.

b) Orações relativas complexas, com cujo ou constituintes preposicionados, são aprendidas na escola, e restringem-se à escrita.

c) O pronome relativo cujo está em desuso, sendo substituído por outros pronomes relativos ou por outras construções.

\section{Considerações iniciais sobre a construção relativa}

Tarallo (1983) identificou três tipos de orações relativas na análise da fala popular de São Paulo: 
a) variante com lacuna, que é idêntica às orações relativas encontradas na língua escrita padrão.

Exemplo:

Tem as que não estão nem aí, não é?

Ela recebe esse nome porque há uma lacuna na oração relativa na posição original do SN-qu, e ocorre somente nas funções de sujeito e de objeto direto.

b) variante do pronome resumptivo, que não envolve lacuna, pois essa posição é preenchida por forma pronominal correferente com o SN núcleo da relativa.

Exemplo:

Você acredita que um dia teve uma mulber que ela queria que a gente entrevistasse ela pelo interfone?

Segundo Tarallo, essa forma seria perceptualmente mais acessível e utilizada em muitas línguas apenas como último recurso de expressão, como é o caso do inglês. Essa estratégia ocorre, ao contrário do primeiro tipo, na escala sintática inteira ${ }^{1}$.

c) a relativa cortadora é o terceiro tipo e ocorre quando o $\mathrm{SN}$ relativizado é o objeto de uma preposição. Nesse tipo de relativa, estão ausentes a preposição regente e o SN relativizado, sendo também uma variante com lacuna.

Exemplo:

E um deles foi esse fulano aí que eu nunca tive aula $\emptyset$.

Em função do objetivo que se tem aqui, serão considerados apenas os tipos b) e c) para análise.

$\mathrm{O}$ autor, na mesma investigação, fez também um estudo diacrônico das três estratégias (padrão, com pronome resumptivo e cortadora), em quatro períodos de tempo: I) primeira metade do século XVIII; II) segunda metade desse mesmo século; III) primeira metade do século XIX; e IV)

1. É o que Lemle (1978), chama de relativa copiadora. 
segunda metade do século XIX. Para esse trabalho, recolheu cartas pessoais, diários e textos teatrais, que abrangiam esses períodos. Os resultados são os da tabela seguinte:

Tabela 1: Freqüência do uso das três estratégias de relativização em quatro períodos de tempo ${ }^{2}$

\begin{tabular}{|c|ccccc|}
\cline { 2 - 6 } \multicolumn{1}{c|}{} & I & II & III & IV & Total \\
\hline standard & 383 & 384 & 385 & 254 & 1406 \\
& $95,7 \%$ & $96,0 \%$ & $96,9 \%$ & $67,1 \%$ & \\
resumptive & 16 & 12 & 9 & 19 & 56 \\
& $4,0 \%$ & $3,0 \%$ & $2,6 \%$ & $5,0 \%$ & \\
PP-chopping & 1 & 4 & 6 & 106 & 117 \\
& $0,3 \%$ & $1,0 \%$ & $1,5 \%$ & $27,9 \%$ & \\
TOTAL & 400 & 400 & 400 & 379 & 1579 \\
\hline
\end{tabular}

Observa-se, no estudo de Tarallo, que a opção pela relativa padrão se mantém estável nos três primeiros períodos, perdendo terreno no quarto. A relativa com pronome resumptivo se mantém, como diz o autor, marginalmente ao longo dos quatro períodos. Agora o que realmente é mostrado de forma significativa é o fato de que, justamente no período em que diminui a preferência pela relativa padrão por parte dos informantes, a cortadora emerge, e se mantém até hoje, como se verá também nos dados aqui analisados. O autor demonstrou que o relativo cujo e outros constituintes preposicionados, que envolvem movimento para o início da sentença, estão desaparecidos da língua falada, o que pode ser visualizado na tabela seguinte:

2. Tabela extraída de Tarallo (1983: 206). 
Tabela 2: Freqüência de preenchedores de COMP em orações adjetivas (Tarallo, 1994:168)

\begin{tabular}{|l|c|c|}
\cline { 2 - 3 } \multicolumn{1}{c|}{} & Ocorrências & $\%$ \\
\hline O qual /os quais & - & - \\
A qual / as quais & - & - \\
Cujo/cuja/cujos/cujas & - & - \\
Quanto/quanta/quantos/quantas & - & - \\
Que & 1681 & 98,9 \\
Onde & 13 & 0,7 \\
Preposição + que & 5 & 0,3 \\
Preposição + o qual & 1 & 0,1 \\
Total & 1700 & 100,0 \\
\hline
\end{tabular}

Os dados da tabela acima mostram a clara e expressiva preferência pelo relativo que, a inexistência de construções com cujo e a baixa ocorrência de preposiçãa + pronome relativo (apenas seis ocorrências, de um total de 1700 orações relativas encontradas). Não se deve deixar de registrar ainda o segundo pronome relativo mais usado, onde, que possui uma preposição no seu étimo.

Os resultados encontrados por Tarallo (1983) que apresentamos acima servem de base para o estudo que se fará aqui.

\section{Metodologia}

Analisam-se neste estudo dados do Atlas Lingüístico Diastrático e Diatópico del Uruguay - ADDU - Norte ${ }^{3}$, correspondente ao norte bilíngüe. $\mathrm{O}$

3. Atlas Lingüístico Diatópico y Diastrático del Uruguay (ADDU), é um projeto binacional, coordenado em Montevidéu, no Uruguai, por Adolfo Elizaincín, e em Kiel, na Alemanha, por Harald Thun, e tem por objetivo a descrição da variação lingüística da República Oriental do Uruguai. Os pontos de entrevista estendem-se por todo o território uruguaio, além de alguns pontos externos na Argentina e no Brasil. Esse projeto se divide em duas partes: ADDU e ADDU-Norte, que contempla a lusofonia. Os dados coletados são fonéticos, lexicais, morfossintáticos, pragmáticos e, em alguns casos, etnográficos. Foram coletados entre 1989 e 1992 por diversos grupos de entrevistadores de ambos os países. 
ADDU-Norte reúne entrevistas com lusofalantes ${ }^{4}$ do lado uruguaio, bem como de falantes de português do lado brasileiro. Dessas entrevistas, serão examinados dados de dois estilos: pergunta/resposta e conversa livre. Do estilo pergunta/resposta, serão consideradas as respostas às perguntas 674 , 677 e 678 do questionário para o português, em que é investigada a consciência dos informantes em relação às relativas complexas (com o uso de cujo e preposição + que). Os dados do estilo conversa livre são os que foram obtidos com os comentários tecidos pelos informantes em relação à língua que falam. Se nesse recorte não houve a ocorrência de relativas, se procedeu a outro recorte, em que se presumia a ocorrência de relativas: no relato de histórias orais. Para essa finalidade, foi escolhida a pergunta 203 do questionário para o português, em que, perguntados como se chama o sétimo filho, quando os outros foram também homens (cuja resposta é lobisomem), os informantes eram solicitados a contar uma história de lobisomem que conhecessem e explicar como se dá a transformação.

Além dos dados do ADDU, examinaram-se cinco entrevistas do projeto Norma Urbana Culta - NURC-Porto Alegre, para verificar como o fenômeno se manifesta entre falantes de alta escolaridade. Esses dados correspondentes ao português sul-americano são comparados com os do português europeu (PE). Para contemplar esse grupo, foram usadas as entrevistas do projeto Português Fundamental'5.

4. A presença do português em território uruguaio é tão antiga quanto a história da região, uma vez que os portugueses foram os primeiros a se estabelecer ali e somente a partir do século XIX, através de uma política de castelhanização, o espanhol conseguiu se impor, ainda que, na esfera familiar, se tenha continuado a falar o português. (Thun, 1986)

5. Trata-se de um banco de dados que pretende ser uma mostra do português europeu falado na atualidade. Os informantes têm idade entre 15 e 70 anos, são homens e mulheres, provenientes de área rural e urbana, e das mais variadas profissões. Mas, como a intenção, segundo os organizadores, era uma representação do falar urbano, metade do corpus é composto por informantes provenientes de Porto, Coimbra e Lisboa. No que diz respeito à escolaridade, estão divididos em seis grupos, de analfabetos a informantes com curso superior completo, a maioria deles, entretanto, são informantes do tipo "médio". Os autores afirmam que "a maior parte dos indivíduos tem um desempenho lingüístico médio e só as minorias têm um desempenho lingüístico inferior ou superior, sendo essas minorias equivalentes. Assim, optou-se por uma concentração das realizações na zona de qualidade média, uma vez que as freqüências mais caracterizadoras do comportamento lingüístico são produzidas por falantes de nível de instrução médio“. (Nascimento/Marques/Cruz, 1987:19) 


\section{Análise e discussão dos resultados}

Como mencionado acima, investiga-se o uso da preposição diante do pronome relativo, em dois estilos. Comecemos com a consciência lingüística que os falantes têm em relação ao uso de relativas complexas ${ }^{6}$, manifestada no estilo pergunta/resposta.

\subsection{O estilo pergunta/resposta e a consciência lingüistica dos falantes}

A pergunta 674 do questionário do ADDU-Norte refere-se ao uso de cujo $^{7}$. Nessa pergunta, ao serem questionados sobre como reconstruiriam a frase dada, os informantes podiam optar entre a alternativa com cujo (obedecendo às regras da língua padrão ${ }^{8}$ ou não) e a com o uso de que. Em função do objetivo que se tem aqui, serão consideradas somente a resposta padrão e a com que (que representa a relativa cortadora). $\mathrm{O}$ resultado da opção dos informantes pode ser visualizado nos mapas 1 e 2 , em anexo.

A análise desses mapas nos mostra que a construção relativa com cujo é desconhecida da maioria dos informantes, ao contrário daquela com que, informada como conhecida e usada pela maioria deles. Nota-se que somente os informantes dos grupos Ca (classe alta - informantes que cursaram o ensino secundário ou mais) dizem conhecer e usar a forma (à exceção de um informante grupo de $\mathrm{Cb}$ (classe baixa - informantes que cursaram apenas os primeiros anos da escola). Interessante observar que, quando os

6. Para Focchi (1991), existem os relativos que fazem recuperação simples - que e o qual - cujo sentido será atribuído pelo dado semântico do antecedente, e os de recuperação complexa - quem, onde, cujo, quanto e como - os quais adicionam seus semas particulares à informação recuperada, moldando-lhe o significado. Além disso, acredita-se que também que e o qual, quando precedidos de preposição, se transformam em estruturas complexas, devido ao número de regras envolvidas para fazer o movimento do constituinte preposicionado para encabeçar a oração relativa, e, por isso, essas estruturas são evitadas pelos falantes.

7. 674. Para a frase $\mathrm{O}$ vizinho está desesperado porque a sua filha morreu, posso dizer também

a) $\mathrm{O}$ vizinho cuja filha morreu está desesperado.

b) O vizinho cuja a filha morreu está desesperado.

c) O vizinho cujo a filha morreu está desesperado.

d) O vizinho que a filha morreu está desesperado.

e) O vizinho o qual a filha morreu está desesperado.

8. Usamos, ao longo do texto, língua padrão ou norma padrão para nos referirmos à modalidade escrita. Porém, pessoas com altos graus de instrução podem, em algumas situações, fazer uso, na fala, de uma variedade que se aproxima muito dessa modalidade. 
informantes de Ca dizem apenas conhecer a construção com que, demonstram um juízo de valor em relação a essa estrutura. Essas observações nos levam a pensar em variação diastrática e diafásica para a construção relativa com cujo: parece ser aprendida na escola e ser usada ainda em alguns contextos mais formais.

Nas perguntas 677 e $678^{9}$, é investigado o conhecimento dos informantes em relação a outras construções relativas complexas, características da escrita padrão. Olhemos os mapas 3 e 4, 5 e 6, como também 7 e 8 em anexo, que contemplam as respostas dos informantes. Em relação a esses mapas, é interessante notar que, ao se defrontarem com uma relativa que pode ser construída de diferentes maneiras, os informantes mostram rejeição em relação a "de que" com antecedente [+ humano]; entre "do qual" e "de quem", a última é a preferida. Agora a alternativa favorita mesmo é a cortadora ( $O$ homem que falamos ontem mora perto daqui), como mostra o mapa $6^{10}$.

Outro dado interessante que se pode extrair da observação dos mapas é como a ocorrência da relativa cortadora se mostra diferente nos mapas 6 e 7. A explicação se encontra com os próprios informantes, que identificaram uma ambigüidade nessa construção. Cremos que isso se deva ao fato de que os informantes, ao responderem às questões anteriores, tenham se familiarizado com o assunto e adquirido um conhecimento a respeito. Nas duas perguntas se trata da regência do verbo falar (falar de e falar com). Quando chegam à questão 678, notam ambigüidade com o apagamento da preposição e consideraram importante manter a preposição (ou usar pronome resumptivo, como alguns sugeriram):

9. 677.

O homem do qual falamos ontem mora perto daqui.

$\mathrm{O}$ homem de quem falamos ontem mora perto daqui.

$\mathrm{O}$ homem de que falamos ontem mora perto daqui.

* O homem que falamos ontem mora perto daqui.

678.

Este é o homem que eu falei ontem.

Este é o homem com quem eu falei ontem.

10. Nos pontos em que aparece "sem resultado", as entrevistas já haviam sido feitas com a primeira edição do questionário, que não previa a alternativa "d". Essa alternativa, com a cortadora, foi acrescentada na segunda edição do questionário revisto. Cremos que os resultados dos outros pontos se repetiriam também ali, porque parece não haver variação diatópica para a relativa cortadora. 
E1: E "este é o homem que eu falei ontem" ou "este é o homem com QUEM eu falei ontem" I1: A ver.. como foi a primeira?

E1: "Este é o homem que eu falei ontem"... "Este é o homem com QUEM eu falei ontem"

I1: Ah... esta é a correta... La outra não... Não... porque a outra dá a entender outra coisa

E1: O quê?? "Este é o homem que eu falei ontem"

I1: Porque uma te dá a entender que vos hablaste com este homem... E a outra te dá a entender que vos hablaste del hombre

E1: Ah... então

I1: Porque na outra existe um comentário sobre la persona

E1: $A b$

I1: E la outra dá a entender que vos hablaste com la persona...Por eso te digo... una tá bien e otra tá mal T02 - Ca GI

Segundo explicação de grande parte dos grupos de informantes, ao se omitir a preposição, a frase fica ambígua (como se disse, talvez esse fato tenha chamado a atenção em função da pergunta anterior, cuja estrutura é muito parecida). Assim, justifica-se a preferência dos informantes pela permanência da preposição (e não o seu apagamento, como nas perguntas anteriores). Como solução para a questão da ambigüidade, alguns informantes sugerem a relativa com pronome resumptivo ${ }^{11}$, que não havia sido incluída em nenhuma das versões do questionário:

I1: E o bomem que eu falei ontem... sim é uma forma

E1: E isso o que quer dizer... que eu falei com o bomem ontem?

I1: Sim. Mas

E1: Este é o homem que eu falei ontem

I1: Não... este é o homem que eu falei ontem com ele

E1: Com ele? Ah. Perfeito... sim. É o mesmo que dizer "o homem com QUEM eu falei ontem"

I1: Com quem eu falei ontem.

E1: A mesma coisa?

I1: A mesma coisa. S3 - Cb GII

Podemos observar que, por parte do informante, não há julgamento de valor, importa é a clareza.

\footnotetext{
11. Também nesse caso, no italiano, os informantes, em muitos casos, preferiram marcar a função sintática com a repetição do pronome, como diz Alfonzetti (2002:134): dopo una esitazione tenta di utilizzare la costruzione dello standard scritto, selezionando la forma sensa preposizione, il quale, ma percependo forse una qualche anomalia, renuncia, optando di nuovo per il tipo che con ripresa: Tuo cugino, che $i$ : il quale/che io gli avevo fatto quel favore non mi ba detto neanche grazie (F 41 casalinga)
} 
$\mathrm{Na}$ verdade, quando voltamos aos textos das entrevistas da questão 678 , constatamos que, inicialmente, a primeira alternativa, com o apagamento da preposição, é aceita como bem construída e conhecida, e a ambigüidade não é identificada. Somente quando lhes é apresentada a alternativa seguinte (preposição + pronome relativo) é que os informantes percebem que a ausência da preposição ocasiona um duplo sentido. Não é possível saber aqui se a ambigüidade teria sido percebida, caso não houvesse sido feita a pergunta 677. Ficou claro para os informantes que, com o apagamento da preposição em "O homem que eu falei", a estrutura pode significar tanto que eu falei com ele ou dele, ambigüidade que se resolve somente com a estratégia do pronome resumptivo, sugerida por alguns informantes (ou com a manutenção da preposição diante do pronome relativo).

Vemos, portanto, que, ao relativizar, o falante tem duas alternativas: a omissão da preposição (cortadora) e o preenchimento da função sintática com um pronome resumptivo (copiadora). Diez (1882) já afirmou que, em muitos casos, o relativo que pode substituir um constituinte preposicionado, e, em outros, a função sintática pode ser preenchida por um pronome resumptivo ${ }^{12}$.

Tarallo (1983) mostrou que a relativa cortadora é a estratégia preferida dos falantes quando se trata de complementos e adjuntos preposicionados, enquanto a relativa do pronome resumptivo, segundo ele, é privilegiada pelo genitivo. Os dados que analisamos até aqui nos fazem concordar com o autor em relação à cortadora, de que ela seja usada quando se trata de adjuntos e complementos preposicionados. Basta voltar ao mapa 6, que representa as opções pela alternativa com apagamento da preposição, e compará-lo aos mapas 3, 4 e 5, que visualizam a preferência dos informantes pelas relativas com constituinte preposicionado. Com os dados que analisamos até aqui, não podemos ainda nos posicionar em relação ao fato de que a relativa com pronome resumptivo seja privilegiada pelo genitivo.

$\mathrm{O}$ autor mostra que a variante-padrão (com piedpiping ${ }^{13}$ ), que ocorre na escrita, é realizada de duas formas na fala: a estratégia do pronome

12. No italiano, a situação é a mesma. Segundo Alfonzetti (2002), informantes de Ca usam cui, precedido de preposição (padrão, portanto), mas preposição + quale praticamente inexiste entre esse grupo de informantes; já os de $\mathrm{Cb}$ usam somente che seja qual for a função sintática exercida pelo pronome relativo.

13. Com o movimento do constituinte preposicionado para o início da relativa. 
resumptivo e a cortadora, que não sofre estigma. Entre os informantes do ADDU, percebe-se a dificuldade que representa a elaboração de uma relativa com piedpiping. O texto abaixo exemplifica essa dificuldade (ainda que lhes tenha sido solicitado fazê-lo de forma simples, como falariam no dia-a-dia):

E2: Sim, mas falando mais naturalmente como diriam?

I1: Os filhos cuja mãe morreu

E2: Não, entre amigos

I1: Los hijos que

E1: Não em

I1: $\mathrm{Si}$

E2: Si, não, por exemplo

I2: $O$ bomem

I1: Tá falando da mulher que morreu no?

E1: Não... os filhos

E2: Os filbos daquela

I1: da mãe

E1: Cuja mãe morreu estão desesperados... como diriam isso naturalmente?

E2: Os filhos daquela ... morreu... por exemplo...

I1: Aha... a quem morreu?

I2: Os filhos de quem

I1: Da mãe

I2: Os filhos de quem morreu... quer dizer... ah

I1: De quem morreu o pai ou a mãe

E2: (-? -) Os filhos de quem morreu faz

I1: $\mathrm{Hmm}$

E2: \{-? -) claro

E1: Aha A1 - CaGI

Percebe-se, na fala acima, a dificuldade que representa a construção de uma estrutura relativa, quando envolve movimento de constituinte. Em ambos os grupos (GI - geração jovem, com 18 a 36 anos e GII - geração velha, com mais de 60 anos), os informantes sabem que o pronome relativo substitui um sintagma nominal, mas têm dificuldade de compor a relativa. Sem sugestões do entrevistador, provavelmente não chegariam à resposta. A mesma dificuldade pode ser notada entre os informantes do italiano, que hesitam e se corrigem até chegarem à resposta (que nem sempre segue as regras do italiano padrão):

Tuo cugino...di cui...tuo cugino...che io gli avevo fatto quel favore non mi ha detto nemmeno grazzie (M 26 commerciante) 
Nos dados do ADDU-Norte, repete-se o que Alfonzetti (2002) levantou em relação aos dados do ALS: estruturas possessivas são difíceis de ser construídas e, por isso, evitadas pelos falantes. A opção mais usual, tanto no português quanto no italiano, é o uso de que/che como substituto a cujo/ cui. Porém, enquanto no italiano esse fenômeno ocorre principalmente com informantes de baixa escolaridade (os de $\mathrm{Ca}$ ainda preferem a estrutura com cui, tanto no estilo pergunta/resposta, quanto no estilo conversa espontânea), no caso do português ele se estende a falantes de todos os níveis, não se podendo pensar em variação diastrática para que.

De um modo geral, se analisarmos os mapas dos resultados a todas as perguntas e alternativas oferecidas, verificaremos que os informantes preferem a relativa cortadora, seja em relativa com idéia de posse, seja em relativa em função oblíqua.

Cabe ainda dizer que os informantes identificam as estruturas com cujo e preposição + que como não sendo pertencentes à variedade falada na comunidade, identificando-as a falantes do meio urbano e escolarizados (os "jornalista"), ou ainda como pertencentes ao espanhol.

Para Thun (1991:244-45), ao lado da lingüistica que comprova, que se baseia em dados empíricos, existe a lingüística que imagina, que é uma lingüística popular, proveniente do saber metalingüístico que cada informante tem sobre a sua língua. Para o autor, las opiniones pueden influir en el comportamiento lingüistico o recordar un estado de lengua que ya no existe. Isso explicaria as respostas dos informantes, ainda que, como veremos adiante, não usem o constituinte preposicionado na sua fala espontânea. No momento, entretanto, em que são convidados a se manifestar conscientemente sobre a língua que falam, emitem juízos de valor em relação ao que é mais ou menos adequado.

\subsection{O uso de relativas na conversa espontânea}

Como nos dados de Tarallo (1983), que é o pronome relativo preferido dos falantes, sejam quais forem os dados que se olhem: 
Tabela 3: Uso de pronomes relativos pelos informantes no estilo conversa espontânea

\begin{tabular}{|l|c|c|c|}
\cline { 2 - 4 } \multicolumn{1}{c|}{} & ADDU & NURC & PE \\
\hline que & $229(89,8 \%)$ & $106(83,4 \%)$ & $294(77,6 \%)$ \\
p+que & $1(0,4 \%)$ & $14(11 \%)$ & $49(12,9 \%)$ \\
o qual & 0 & 0 & 0 \\
p+o qual & $1(0,4 \%)$ & $1(0,8 \%)$ & $1(0,3 \%)$ \\
quem & $2(0,8 \%)$ & $1(0,8 \%)$ & $2(0,5 \%)$ \\
cujo & 0 & $1(0,8 \%)$ & 0 \\
onde & $22(8,6)$ & $4(3,2 \%)$ & $31(8,2 \%)$ \\
como & 0 & 0 & 0 \\
quando & 0 & 0 & $2(0,5 \%)$ \\
\hline Total & 255 & 127 & 379 \\
\hline
\end{tabular}

A tabela 3 nos dá uma idéia geral quanto ao tipo de pronome relativo por que os falantes optam nas suas manifestações e é o ponto de partida para nossa análise. Conforme se supunha e já se disse, que é o pronome relativo preferido dos informantes, sendo seguido pelo relativo onde. Notese também que preposição + que tem uma ocorrência maior entre os informantes do NURC e do PE, o que pode estar ligado à escolaridade, pois acreditamos que o movimento do constituinte preposicionado seja uma estrutura adquirida na escola e com exposição a material escrito.

Mas olhemos cada conjunto de dados separadamente.

\subsubsection{Os dados do ADDU}

Na tabela 3, foi possível observar que o relativo que é usado em $90 \%$ das construções aqui analisadas. As relativas dos informantes do ADDU estão resumidas na tabela 4: 
Tabela 4: Construções relativas dos informantes do ADDU

\begin{tabular}{|l|c|}
\cline { 2 - 2 } \multicolumn{1}{c|}{} & ADDU \\
\hline cortadora & $43(56,6 \%)$ \\
p+que & $1(1,3 \%)$ \\
pronome resumptivo & $4(5,3 \%)$ \\
p+o qual & $1(1,3 \%)$ \\
que em lugar de outro relativo & $3(3,9 \%)$ \\
quem & $2(2,6 \%)$ \\
cujo & 0 \\
onde & $22(29 \%)$ \\
como & 0 \\
quando & 0 \\
\hline Total & 76 \\
\hline
\end{tabular}

Entre os falantes do ADDU-Norte, merecem destaque aqui, pela sua freqüência, o uso da relativa cortadora e do relativo onde. Como se vê, mais da metade das tentativas de relativizar um elemento preposicionado foram realizadas através do apagamento da preposição. Também é relativamente grande (quase $30 \%$ das preferências) a construção de relativas através de onde, que tem uma preposição (em) no seu étimo. Já o uso da estrutura preposição + pronome relativo $^{14}$ é inexpressivo (quatro construções ao todo, num total de 5,2\%). Em relação às construções com pronome resumptivo, Tarallo afirma que elas são privelegiadas pelo genitivo. Em nossos dados, além do genitivo, como em

eu tinha um vizinho aí que as galinha dele (-? - )... mas as galinha dele ele botava (cangalha) pra não entrar na borta B1 - CbGII

o pronome resumptivo também foi usado com as seguintes funções:

a) complemento preposicionado:

I1: Não... só o Uruguai, que a gente tá aqui em contagem \{= contato\} com o Uruguai não BC 6 - CbGII

14. Preposição + que; preposição + o qual. 
b) complemento circunstancial:

numa casa que tem ali e ali tinha os pai, e tinha uma escola onde le digo, ali eu aprendi $\mathrm{A} 2$ $-\mathrm{CbGII}$

Interessante aqui observar que o relativo onde encabeça uma copiadora, funcionando como uma conjunção aditiva ${ }^{15}$ :

tinha uma escola e le digo, ali eu aprendi

Nota-se que, ainda que no estilo pergunta/resposta os informantes tenham informado conhecer e usar estruturas complexas, no momento em que falam livremente eles não as usam.

\subsubsection{Os dados do NURC}

Também entre os falantes de alta escolaridade a relativa cortadora é a preferida dos falantes, como se pode observar na tabela seguinte:

Tabela 5: Construções relativas dos informantes do NURC

\begin{tabular}{|l|c|}
\cline { 2 - 2 } \multicolumn{1}{c|}{} & NURC \\
\hline Cortadora & $36(54,6 \%)$ \\
Pronome resumptivo & $14(21,2 \%)$ \\
p+o qual & $1(1,5 \%)$ \\
Que em lugar de outro relativo & $1(1,5 \%)$ \\
quem & $8(12,1 \%)$ \\
cujo & $1(1,5 \%)$ \\
onde & $1(1,5 \%)$ \\
como & $4(6,1 \%)$ \\
quando & 0 \\
\hline Total & 0 \\
\hline
\end{tabular}

15. Em Kersch (1996) já defendemos a idéia de que o relativo onde muitas vezes funciona como conjunção. Esse tipo chamamos de onde discursivo. 
Os dados da tabela 5, se comparados aos da tabela 3, são claros: o uso do constituinte preposicionado para encabeçar a oração relativa é associado à alta escolaridade (cerca de $25 \%$ das construções desse tipo - se somadas todas - ocorreram entre os informantes do NURC, ao passo que, entre os informantes do ADDU, cuja escolaridade é menor, se verifica apenas cerca de $5 \%$ de construções desse tipo). Por outro lado, a freqüência de uso da relativa cortadora é praticamente a mesma, o que mostra que não existe variação diastrática em relação a esse tipo de construção. Além disso, a relativa com pronome resumptivo, que não tem prestígio, tem uma ocorrência maior entre os informantes do ADDU, cuja escolaridade, na maioria dos casos, é baixa. Chama a atenção também que tenha sido mais freqüente entre os informantes do NURC o uso de que para esquivar-se de usar outro pronome relativo, como no exemplo a seguir, em que poderia ter sido usado quando:

É bem diferente do que depois...que a gente::já sabe o resultado - Inquérito $n^{\circ} 121$ - Bobina 29 - Informante $n^{\circ} 133$

\subsubsection{Os dados do Português Fundamental}

A forma como os falantes do português europeu relativizaram um elemento precedido de preposição pode ser visualizada na tabela seguinte:

Tabela 6: Construções relativas dos informantes do PE

\begin{tabular}{|l|c|}
\cline { 2 - 2 } \multicolumn{1}{c|}{} & PE \\
\hline cortadora & $47(32,6 \%)$ \\
p+que & $49(34,1 \%)$ \\
Pronome resumptivo & $7(4,9 \%)$ \\
p+o qual & $1(0,7 \%)$ \\
que em lugar de outro relativo & $5(3,4 \%)$ \\
quem & $2(1,4 \%)$ \\
cujo & 0 \\
onde & $31(21,5 \%)$ \\
como & 0 \\
quando & $2(1,4 \%)$ \\
\hline Total & $144(100 \%)$ \\
\hline
\end{tabular}


Já de saída, os resultados do PE chamam a atenção, a começar pela freqüência de uso da cortadora, que se mostra menor (cerca de $20 \%$ menos em relação aos dados do ADDU-Norte e do NURC). Em segundo lugar, o dado que surpreende sobremaneira: o alto índice de ocorrências de constituinte preposicionado. Como a maioria dos informantes tem escolaridade "média ${ }^{16}$ ", nota-se que, em relação ao pronome resumptivo, a freqüência é praticamente a mesma que a dos informantes do ADDU. Também se aproxima aos dados do ADDU a opção de usar que em lugar de outro relativo. Não se registrou, como se esperava, a ocorrência do pronome relativo cujo, e a opção por onde se aproxima de igual modo aos resultados registrados na análise dos dados da ADDU. Voltemos, então, ao que nos surpreendeu, o uso de preposição + pronome relativo, assunto deste estudo.

Ao ver esse número expressivo de preposições diante do pronome relativo, pensa-se logo nas preposições que os falantes optariam por manter. Isso pode ser visto na tabela 7:

Tabela 7: Preposições usadas na estrutura preposição + que nos dados do PE

\begin{tabular}{|l|c|}
\cline { 2 - 2 } \multicolumn{1}{c|}{} & Número de Ocorrências \\
\hline De & $4(7,6 \%)$ \\
Em & $37(69,8 \%)$ \\
Com & $5(9,4 \%)$ \\
Entre & $5(9,4 \%)$ \\
Por & $1(1,9 \%)$ \\
\hline Total & $1(1,9 \%)$ \\
\hline
\end{tabular}

Os dados da tabela 7 surpreendem mais uma vez, demonstrando quase $70 \%$ de retenção da preposição em diante do pronome relativo. Não temos conhecimento de estudos sobre um fenômeno que poderia ser chamado "emqueísmo". O que verificamos nesses dados é uma preferência

16. Escolaridade média, para os autores do projeto, é que somente poucos informantes têm escolaridade superior e baixa ou nenhuma escolaridade, sendo a maioria deles pertencentes ao grupo intermediário.por isso nível de instrução médio. 
pelo uso da preposição em diante do pronome relativo que, algumas vezes até mesmo quando ela não é exigida pelo verbo, como, por exemplo:

X: a única coisa em que o tribunal lhe interessa Entrevista 0053

Há casos em que observamos a repetição da circunstância de lugar já expressa pela preposição em, através do advérbio ali (uma espécie de relativa com pronome resumptivo, portanto, mas com a repetição do advérbio no lugar do pronome reto):

X: esse império que é uma espécie de coreto em que a coroa está ali Entrevista 0111

Ou ainda, como na primeira ocorrência do exemplo seguinte, para fazer remissão a uma circunstância de tempo:

$X$ : um dia em que estava a tratar dum inventário, portanto de uma herança em que havia dum lado os órfãozinhos Entrevista 0232

A tendência de nas línguas românicas se apagar a preposição em diante de que nas circunstâncias de tempo e lugar, conforme Diez (1882), parece não se verificar nos dados desta amostra do PE. Se temos esse grande número de ocorrências de preposição + pronome relativo, então poderíamos pensar que o número de relativas cortadoras devesse ser bem menor no PE, o que não se verificou, se comparamos os resultados do $\mathrm{PE}$ aos do $\mathrm{ADDU}^{17}$.

Como o número de ocorrências de relativas cortadoras não se mostrou tão menor entre os falantes de PE, somos levados a crer que a maioria das construções preposição + que sejam padrão, uma vez que esses informantes apresentam uma porcentagem de $20 \%$ a mais em relação aos do ADDU. É o que se pode verificar na tabela seguinte:

Tabela 8: Distribuição da estrutura preposição + que entre ocorrrências padrão e não-padrão no PE

\begin{tabular}{|l|r|}
\cline { 2 - 2 } \multicolumn{1}{c|}{} & \multicolumn{1}{c|}{ Ocorrências } \\
\hline Padrão & $45(84,9 \%)$ \\
não-padrão & $8(15,1 \%)$ \\
Total & $53(100 \%)$ \\
\hline
\end{tabular}

17. Veja-se tabelas 4 e 6. 
A tabela 8 nos apresenta um resultado que surpreende novamente se comparado aos resultados do português brasileiro: nos dados do PE encontramos não somente um grande número de ocorrências de preposição diante do pronome relativo, como também a grande maioria delas é padrão. Além disso, em uma grande quantidade delas, se verifica a manutenção da preposição em nas circunstâncias de tempo e lugar. Diez (1882) já havia registrado a possibilidade de a palavra que substituir qualquer pronome relativo precedido de preposição em várias situações, dando exemplos do espanhol, italiano e francês. Talvez Diez não tenha apresentado exemplos do PE porque realmente isso não seja tão freqüente nessa variedade.

Resta saber agora se preposição + pronome relativo é usada entre informantes de todas as escolaridades, ou se é um uso de um determinado grupo. É o que se esclarece a tabela seguinte:

Tabela 9: Retenção da preposição diante de que no PE, considerando a escolaridade

\begin{tabular}{|l|c|}
\cline { 2 - 2 } \multicolumn{1}{c|}{} & Ocorrências \\
\hline Grupo 0 (analfabetos) & 0 \\
Grupo 1 (nível primário) & 1 \\
Grupo 2 (primeiro ciclo liceal) & 3 \\
Grupo 3 (segundo ciclo liceal) & 7 \\
Grupo 4 (terceiro ciclo liceal) & 10 \\
Grupo 5 (freqüência universit.) & 5 \\
Grupo 6 (curso superior) & 20 \\
\hline Total & 46 \\
\hline
\end{tabular}

E aqui está: no PE se confirma a hipótese de que a produção de um número maior de relativas nas manifestações espontâneas está ligada à maior escolaridade e que também o tipo de relativa produzida está relacionado à escolaridade do falante. A tabela 9 é clara: quanto maior a escolaridade, maior é o índice de retenção da preposição diante do pronome relativo (à excecão, apenas aparente, do Grupo 5, de que, entretanto, se tem um número menor de entrevistas). Mas, se comparamos os dois extre- 
mos (grupo 0 e grupo 6), vemos claramente que a escolaridade influencia no tipo e na quantidade de relativas produzidas $^{18}$.

\section{Considerações finais}

Com base no que apresentamos até aqui, podemos fazer algumas afirmações acerca do uso do constituinte preposicionado por falantes do português brasileiro e português europeu. No estilo pergunta/resposta, informantes da fronteira Brasil-Uruguai, que pertencem aos grupos $\mathrm{Cb}$ (de baixa escolaridade) identificam cujo como sendo espanhol e sugerem estruturas alternativas para cujo, tais como o uso de outro relativo, de coordenada aditiva ou de subordinada causal. Além disso, informam conhecer do qual, mas preferem de quem quando o antecedente é [+ humano] e rejeitam a forma de que para antecedente [+humano]. O apagamento da preposição diante do pronome relativo (cortadora) é a estratégia preferida por esses informantes, mas recomendam o uso da preposição ou o uso do pronome resumptivo para evitar ambigüidade. O conhecimento da função que o pronome relativo exerce na oração só se verifica entre os informantes de $\mathrm{Ca}$, de escolaridade secundária ou superior, demonstrando que as relativas complexas são aprendidas na escola e em contato com material escrito.

No estilo conversa espontânea, orações com o relativo que são as mais freqüentes, podendo ser verificado que esse relativo também é usado para substituir um outro relativo, com o falante evitando a construção de uma relativa complexa. Em caso de ambigüidade, ou a preposição é mantida, ou é usado um pronome resumptivo. O relativo cujo inexiste no português brasileiro falado, bem como nos dados do português europeu que analisamos.

Os constituintes preposicionados, com seu movimento para encabeçar a relativa, estão em desuso no $\mathrm{PB}$, mas ainda muito freqüentes no $\mathrm{PE}$, onde, por exemplo, o apagamento da preposição em nas circunstâncias de tempo e lugar, fenômeno comum em todas as línguas românicas, não é verificado. Além disso, a grande maioria das construções com preposição

18. Convém lembrar que aqui estão excluídas as relativas produzidas na função de sujeito e de objeto direto, uma vez que nos interessavam aqui apenas as construídas com constituinte preposicionado.. 
diante do pronome relativo se realizam com o uso da preposição em, seguindo o padrão escrito. Também entre os falantes do PE se pôde comprovar que o uso de um número maior de orações relativas na língua falada está relacionado à escolaridade, em especial a manutenção da preposição diante do pronome relativo.

Por fim, vale lembrar que o pronome relativo que está em segundo lugar na preferência dos falantes de português é o relativo onde, mas isso já foi ${ }^{19}$ e é assunto para outro estudo.

Recebido em maio de 2006 Aprovado em outubro de 2007 E-mail: dorotea_fk@hotmail.com

\section{REFERÊNCIAS BIBLIOGRÁFICAS}

Alfonzetti, Giovanna. 2002. La relativa non-standard: italiano popolare 0 italiano parlato? Palermo: Centro di Studi Filologici e Linguistici Siciliani.

DiEz, Friedrich. 1882. Grammatik der romanischen Sprachen. Bonn: Edward Weber's Verlag.

Focchi, Eliana. 1991. A classe dos pronomes relativos. ALFA, São Paulo. V. 35. p. $105-122$.

Hilgert, José Gaston (org.). 1997. A linguagem falada culta na cidade de Porto Alegre. Passo Fundo: Editora Universitária.

Kersch, Dorotea Frank. 1996. A palavra ONDE no português do Brasil. Dissertação de Mestrado. Instituto de Letras, Universidade Federal do Rio Grande do Sul, mimeo.

Lemle, Miriam. 1978. Heterogeneidade Dialetal: um apelo à pesquisa. Tempo Brasileiro, 53/54: 60-94.

Nascimento, M. F. B. do; Marques, M. L. G., Cruz, M. L. S. 1987. Português

Fundamental. Métodos e Documentos, Volume 1. Lisboa: Instituto Nacional de Investigação Científica.

Tarallo, Fernando. 1983. Relativization strategies in Brazilian Portuguese. Philadelphia, University of Pennsylvania, PhD Dissertation, mimeo.

19. Kersch, 1996. 
Tarallo, Fernando. 1994. Tempos lingüísticos: itinerário bistórico da língua portuguesa. São Paulo: Ática.

Thun, Harald. 1986. Zum Status der Spanisch-Portugiesischen Sprachmischung im Norden Uruguays. in Neue Romania. Sonderheft: Romanischen Sprachen außerhalb Europas. p. 37-74.

Thun, Harald \& Euzarncín, Adolfo. (1989, $\left.{ }^{2} 1990,{ }^{3} 1992\right)$. Atlas lingüístico Diatópico y Diastrático del Uruguay (ADDU). Questionário português. [s.n.] Mainz.

Thun, Harald. 1996. Movilidad demográfica y dimensión topodinâmica. Los montevideanos em Rivera. In Neue Wege der Romanischen Geolinguistik. Akten des Symposiums zur Empirischen Dialektologie (Heidelberg/Mainz 2124.10.1991. Kiel: Westensee-Verlag Kiel, p.210-269. 